\section{Neoartesanías: reconfiguraciones en el campo artesanal}

Mirta Bialogorski ${ }^{(1)}$ y Paola Fritz ${ }^{(2)}$

Resumen: El Museo de Arte Popular José Hernández se focaliza en las artesanías y los artesanos en tanto producciones y productores culturales. Como actor fundamental de los procesos de patrimonialización está atento a los cambios que experimenta el campo artesanal según los lugares y momentos históricos.

Desde hace un tiempo visualizamos ciertas transformaciones en la producción de artesanías que si bien son disímiles entre sí, nos llevan a preguntarnos si podríamos identificarlos como un nuevo fenómeno: la "neoartesanía".

Se trata de objetos que unen componentes, elementos o procesos tradicionales con otros innovadores. Encontramos que esta producción comienza a darse en trabajos colaborativos entre artesanos, comunidades de artesanos, diseñadores, técnicos, otros profesionales o bien son llevadas a cabo por un mismo artesano. Está atravesada asimismo, por la problemática de la sustentabilidad.

En este trabajo haremos referencia a cómo se construye dicho fenómeno en la Argentina atendiendo a la dispersión de elementos que lo constituyen, cómo se configura la noción de neoartesanía en el discurso de técnicos, artesanos e investigadores teniendo en cuenta casos y contextos particulares. Haremos también una breve referencia a cómo se entiende en otros ámbitos iberoamericanos. Lejos de definir una categoría nos interesa captar las diversas dimensiones que presenta la neoartesanía como parte de un fenómeno social más abarcativo como es el campo artesanal en el actual contexto de globalización.

Palabras clave: neoartesanía - campo artesanal - diseño - sustentabilidad - trabajo colaborativo.

[Resúmenes en inglés y portugués en las páginas 43-44]

(1) Mirta Bialogorski es Doctora en Antropología (Universidad de Buenos Aires). Licenciada en Ciencias Antropológicas, Facultad de Filosofía y Letras (UBA). Se ha dedicado al estudio de temas de patrimonio cultural, museos y visitantes. Es responsable del área de investigación y coordinadora del taller de Estudios de Público en el Museo de Arte Popular José Hernández (GCBA). Como especialista en temas de patrimonio cultural, interculturalidad y migración ha participado en diferentes proyectos de investigación, nacionales e internacionales, y es autora, de numerosos artículos sobre dichas temáticas.

(2) Paola Fritz es Licenciada en Comunicación Social con orientación en planificación institucional (UNLP) especializada en la divulgación y gestión del patrimonio cultural. 
Actualmente coordina el área de Comunicación y Promoción Artesanal del MAP Museo de Arte Popular José Hernández (Ministerio de Cultura - Gobierno de la Ciudad de Buenos Aires). Es además profesora de ‘Teoría de la Comunicación' en la Escuela Nacional de Museología (Ministerio de Cultura de la Nación). Se dedica asimismo a la investigación y gestión de proyectos relacionados con comunicación y patrimonio cultural, con publicaciones sobre el tema.

El MAP Museo de Arte Popular José Hernández, de la ciudad de Buenos Aires (Argentina) se focaliza en las artesanías, y en las artesanas y artesanos en tanto producciones y productores culturales respectivamente. Como actor fundamental de los procesos de patrimonialización, está atento a los cambios que experimenta el campo artesanal según los lugares y momentos históricos.

Su patrimonio está constituido por artesanías tradicionales (indígenas y criollas) y urbanas/contemporáneas representativas de diferentes especialidades, técnicas y materiales. Se trata de producciones de los siglos XIX, XX y XXI, de origen tanto urbano como rural cuyos usos son de tipo utilitario, ceremonial y simbólico. Fueron realizados, con diferentes materiales y técnicas, por artesanas/os indígenas, mestizos y criollos, así como por artesanas/os inmigrantes españoles, italianos, franceses o sus descendientes.

La historia de los procesos de patrimonialización que atravesó esta institución desde su creación en 1948 hasta el día de hoy permite dar cuenta de los cambios que viene experimentando el campo artesanal en nuestro país poniendo en tensión, por un lado, categorías propias del mismo y por otro, mostrando la emergencia de nuevas configuraciones.

Desde hace un tiempo hemos observado cierto tipo de transformaciones en los procesos de producción artesanal y en los productos que, si bien son disímiles entre sí, nos llevan a preguntarnos si podríamos identificarlos como un nuevo fenómeno: la "neoartesanía". Esta noción involucra el cruce de la artesanía tradicional y contemporánea o urbana con el campo del diseño y la tecnología, aborda la problemática de la sustentabilidad y muestra una modalidad de trabajo colaborativo entre artesanos, comunidades de artesanos, diseñadores, técnicos y otros profesionales.

En este trabajo haremos referencia a cómo se construye dicho fenómeno en la Argentina atendiendo a la dispersión de elementos que lo constituyen, cómo se configura la noción de neoartesanía en el discurso de técnicos, artesanos e investigadores teniendo en cuenta casos y contextos particulares. Haremos también una breve referencia a cómo se entiende en otros ámbitos iberoamericanos.

Lejos de definir una categoría nos interesa captar las diversas dimensiones que presenta la neoartesanía como parte de un fenómeno social más abarcativo como es el campo artesanal en el actual contexto de globalización. 


\section{Neoartesanía: un fenómeno en construcción en el campo artesanal}

El campo artesanal está constituido por un conjunto de prácticas y representaciones culturales específicas sobre el trabajo, el arte y las tradiciones culturales de determinados sectores sociales (poblaciones rurales, comunidades indígenas, trabajadores de oficios urbanos).Es un espacio heterogéneo de producción y reproducción de bienes culturales cuyos bordes se redefinen histórica y socialmente (Bialogorski, 2016). En la Argentina y en el contexto iberoamericano advertimos la aparición cada vez más frecuente de artesanías que no podrían definirse sólo como tradicionales (criollas o de pueblos originarios), ni como únicamente contemporáneas ya que combinan elementos de unas y otras.

Partimos de la base de que dichos conceptos como tales son construcciones sociales, dinámicas, con bordes en permanente cambio, muchas veces difusos que varían temporal y espacialmente. Se trata de objetos que presentan las características propias de la artesanía, esto es la transformación de la materia prima en un alto grado y una funcionalidad reconocible siendo además, una manifestación portadora de una identidad, una cultura y una estética particular. Cuentan simultáneamente con la presencia de un factor tradicional y uno innovador, ya sea en lo que respecta a materiales, técnicas, diseños o la fusión entre unos y otros, ya sea en relación a los procesos de elaboración como puede ser por ejemplo, la co-creación entre artesanos, artesanos y diseñadores en la mayoría de los casos u otros profesionales -ingenieros, arquitectos, informáticos-.

Las circunstancias por las que aparece este tipo de artesanías sin duda forman parte de la contemporaneidad y de lo que ésta trae aparejado: el desarrollo del sistema capitalista, la interacción entre lo global y lo local y la problemática de la sustentabilidad. Observamos que en este contexto las artesanías se integran a nuevos conceptos de usos (o utilidad), a modas, tendencias, nuevas tecnologías y a los planteos actuales acerca de la crisis medioambiental.

En Argentina el término "neoartesanía" ha sido utilizado en la década de 1970 por el estudioso Augusto Raúl Cortazar (1976) para referirse a aquellas producciones elaboradas en el ámbito urbano y cosmopolita a diferencia de las artesanías tradicionales. También se las denominó "urbanas o contemporáneas" entendiéndolas como objetos útiles y bellos que recurren a la tecnología moderna y a principios estéticos de tendencia universal o académica en las cuales se destaca la creatividad individual y la originalidad del estilo (Bialogorski y Fritz, 2011).

En el MAP recién a principios del siglo XXI comenzaron las gestiones para incluir a las artesanías urbanas como patrimonio cultural de la Ciudad de Buenos Aires. Por una decisión conjunta de la Comisión para la Preservación del Patrimonio Histórico y Cultural de la Ciudad de Buenos Aires (CPPHC) y el MAP se fundó en el 2003 el Programa de Artesanías Urbanas cuyos objetivos fueron: crear una colección de artesanías contemporáneas; organizar el concurso de la Bienal de Artesanías de Buenos Aires; realizar relevamientos de artesanos/as de la ciudad así como de los diversos agentes vinculados a la actividad artesanal; formar público sensible que pueda discernir, identificar, valorar a las artesanías en sus especificidad, y para esto realizar estudios de público con un enfoque predominantemente cualitativo y finalmente, asesorar a los artesanos/as, autoridades, organizaciones públicas o privadas que apoyaban a las artesanías y a sus productores. 
Con esta colección y las adquisiciones a través de los concursos de la Bienal fundamentalmente, se empezaron a vislumbrar en algunas obras ciertas características novedosas que comenzaron a transformar los bordes del campo artesanal tales como el trabajo colaborativo entre artesano y diseñador, la fusión de materiales y/o técnicas tradicionales en formatos modernos y el reciclado. Es decir, se presentaron artesanías que, además de ser urbanas / contemporáneas mostraban cualidades diferenciales. Solo algunos ejemplos: En la I Bienal, en 2005 se presentó una obra emblemática que dio lugar a reflexiones y discusiones. Se trataba de un moderno mate geométrico con bombilla, fusión de madera y metal. Lo particular, además, fue que la elaboración de la pieza estuvo a cargo de un artesano joyero, Juan Manuel Malm Green y un diseñador, Hugo Ambrosio. Esta asociación/ disociación entre el diseñador y el ejecutor de la obra marcó un punto de quiebre en la interpretación de las artesanías tal como se las venía concibiendo en el contexto del museo en tanto producto exclusivo del artesano.

En la II Bienal, el premio adquisición en el rubro metal lo obtuvo Lilia Breyter, ingeniera electrónica y especialista en joyería y textil, con una pulsera que diseñó a partir de un telar tradicional creado por la artesana especialmente para el trabajo con metales nobles. Observamos aquí la utilización de técnicas y materiales tradicionales en una moderna conjunción entre ambos.

En la III Bienal el Premio adquisición en joyería fue para la obra Reflejos, un espejo con estuche de metal y madera realizado por el artesano Pablo Flores quien fusionó técnicas y materiales lo que de alguna manera, impedían encuadrar a la obra en un determinado rubro.

Ya en la IV Bienal, y siguiendo esta misma línea Cristian Roa, reconocido artesano joyero obtuvo el Premio adquisición presentando el broche Satélites fusionando también distintos materiales tradicionales como metal, maderas junto a otros modernos como acrílicos, materiales sintéticos y papeles reciclados. Ejemplos que nos permiten destacar en general las múltiples y sorprendentes variantes de materiales que se presentan en la actualidad en la joyería contemporánea.

En todos los casos comenzaron a tensarse los bordes del campo particularmente, en términos de la definición de rubros vigentes en convocatorias, reglamentos, ferias, etc. y sus cruces así como con la introducción de nuevos materiales. Con la organización de exposiciones y concursos de joyería contemporánea se planteó además de la fusión, el concepto de experimentación en el trabajo artesanal.

En base a estas tendencias nos propusimos desde el MAP investigar sobre estas producciones novedosas que en el campo artesanal se las comenzaban a mencionar como neoartesanías, ya no para diferenciarlas meramente de las tradicionales habida cuenta de que en ellas se entrecruzan lo tradicional y lo moderno, sino para abordarlas como una variante dentro de las artesanías contemporáneas. Para ello consultamos con expertos, artesanos, además de registrar qué ocurría en otros contextos iberoamericanos. 


\section{El debate sobre el concepto de neoartesanía en Argentina}

En Argentina, hay un debate interesante sobre la neoartesanía del que participan artesanos, diseñadores y agentes del campo artesanal (capacitadores, referentes, especialistas). En base a los discursos que hemos registrado no hay consenso en la utilización de esta expresión ya que mientras para algunos la neoartesanía evidencia una innovación dada por la fusión entre lo tradicional y lo urbano, para otros, incluye sólo a las artesanías urbanas y excluye a las artesanías tradicionales y su carácter también de innovación.

"Me parece, dice Roxana Amarilla (gestora cultural y Directora del MATRIA) que (la noción de neoartesanía) deja fuera de la contemporaneidad a la artesanía, al objeto tradicional que es una producción muy vital de hoy día de gran parte de los artesanos argentinos". Se pueden advertir, explica, cambios en los formatos de las piezas para adaptarlas a la demanda del mercado o en los procesos de producción (por ej. la utilización de hornos eléctricos para la arcilla en vez de los hornos tradicionales) (Amarilla, 2020).

Cabe preguntarse en todo caso, qué sucede con las artesanías tradicionales a través del tiempo. Las técnicas, el modo de transmisión, los materiales ¿se transforman o permanecen inalterables?

A la hora de tratar de circunscribir el campo de la neoartesanía, observamos que hay distintas posiciones a veces contradictorias entre sí. Es interesante notar que mientras para algunos especialistas el término es "viejo" -surgido como vimos, en la década de 1970- y no alude a un fenómeno novedoso, para otros en cambio, da cuenta de procesos actuales de producción donde se evidencia ya no una diferenciación entre lo tradicional y lo moderno, como decíamos, sino un entrecruzamiento.

A su vez, para algunos expertos la neoartesanía debería definirse por el uso de materiales no tradicionales, para otros, en cambio, por la utilización de las técnicas y herramientas en el proceso de producción.

Consultados los artesanos encontramos también puntos de vista diferentes. Conforme a la visión de una artesana textil muy reconocida, Vanina Bujalter, si bien no se trata de un concepto antiguo tampoco puede considerarse totalmente disruptivo. En sus palabras "aunque vamos hacia esa dirección no podemos hablar aún de neoartesanías sino más bien de un proceso que nos puede llevar a ellas" afirma, ya que, considera, "se trata de un movimiento que no ha alcanzado aún el punto de revolucionar el campo artesanal”.

Por el contrario, dos artesanas -Silvia Roldán y Lilia Breyter, textil y joyera respectivamente- lo ven como un espacio diferente, definido, que tiene ya sus límites aunque "es dinámico y está en constante transformación".

Es interesante observar cómo algunos artesanos conciben sus obras en tanto neoartesanías aludiendo al aspecto conceptual.

La joyera Hebe Argentieri apunta a la elaboración material y conceptual de sus piezas en cuanto combinan técnicas ancestrales de joyería con materiales contemporáneos: “Así es que junto a los metales clásicos de la joyería, explica, se incorporan plásticos, papeles, textiles (....) privilegiando la intención, el efecto, el deseo generador".

Por su parte, el artesano ceramista Diego Gon hace hincapié en la unión de saberes tradicionales y urbanos/ contemporáneos. En sus obras combina los saberes de los pueblos originarios en técnicas de cestería y su propia formación e impronta en el trabajo con la 
cerámica realizando piezas únicas en una fusión poco habitual. Utiliza además en este último caso, procesos tecnológicos "fuera del campo de la artesanía tradicional como es la generación de las formas por medio del torno alfarero y una extrusora o la quema en alta temperatura (cerámica gres)". También el ceramista Guillermo Silpituca recurre a la tecnología actual aplicada al "arte del fuego" y explica:

En todas mis piezas utilizo la arcilla como material pero el modelado base es a través de software que aplican funciones matemáticas, funciones paramétricas, todo en computadora, y luego impresión 3D directa de la arcilla, para llevar lo que está en el mundo virtual a la realidad física.

¿Puede la impresión 3D/4D considerarse artesanía? Parte del proceso de diseño y creación, la relación con el material, la carga identitaria, el impacto ambiental, la estética de los productos permite considerarla dentro del campo artesanal (Piñeiro, 2011).

Desde el MAP y a raíz de una convocatoria efectuada a artesanos/as para organizar una muestra focalizada en este tipo de producción, registramos diferentes fórmulas que, según los propios protagonistas, la caracterizan. Lo que resalta en todas ellas no es el diseño, el formato, la técnica o el material por sí mismos sino la combinación de estos elementos de diferentes formas. Es así que la Neoartesanía aparece asociada a obras que reúnen:

- Técnicas y materia prima tradicionales +experimentación morfológica y/o tipología híbrida

- Técnicas y materia prima tradicionales + técnicas contemporáneas

- Técnica tradicional + técnica contemporánea + fusión de materiales

- Técnicas tradicionales + fusión de materias primas tradicionales y contemporáneas

- Materia prima tradicional + nueva tecnología

- Fusión de materias primas + técnicas tradicionales + nuevas tecnologías

- Técnicas tradicionales + experimentación morfológica+fusión de materiales

- Técnicas tradicionales + materiales novedosos

Como puede observarse, la noción de neoartesanía se va construyendo al poner en juego la fusión de materiales y rubros, la articulación entre lo tradicional y lo moderno, ocupando las nuevas tecnologías un lugar importante. A ello hay que agregar, como dice la diseñadora y experta Ximena González Eliçabe en una comunicación personal, los procesos de producción que atañen al artesano como productor. Esto es, su participación total o parcial en el producto final y el acceso - muchas veces dificultoso- a las materias primas naturales $\mathrm{y} / \mathrm{o}$, como veremos, a materiales ya procesados.

\section{Neoartesanía y sustentabilidad}

En relación con lo anterior y vinculado a la noción de neoartesanía es relevante destacar la problemática de la sustentabilidad respecto de la utilización de materiales, la suplan- 
tación de los mismos, el nexo de los y las artesanas con el entorno y el mensaje que se quiere transmitir con estas obras. En el discurso del ya citado artesano joyero Cristian Roa aparece mencionado el uso de materiales reciclados o la reutilización de otros como por ejemplo metales que pueden ser descarte de la industria, acrílicos u otros materiales sintéticos, incluso los papeles reciclados: "Como artesanos que transformamos la materia prima, afirma, no debemos exigirle tanto a la naturaleza. No demandar material que implique, a gran escala, extractivismo, deforestación, etc. aunque las artesanías insuman pequeñas cantidades".

El vínculo que siempre ha establecido el artesano con la naturaleza es de respecto, aún si extrae de la misma los materiales son en pequeña escala, lo que permite al recurso su renovación, además de que la característica general de la artesanía es que lejos de ser descartable, puede durar por generaciones, sea por su uso o su representatividad cultural.

El extractivismo a gran escala, los desmontes, la propagación de monocultivos como la soja trajo aparejado en distintas comunidades de Argentina no solamente el desplazamiento de sus lugares de origen y el achicamiento - cuando no desaparición de sus territorios-, sino además dejó fuera del alcance los materiales naturales de las artesanías que se producen.

El problema de las restricciones del acceso a los campos y que muchos artesanos necesitan ir cada vez más lejos a buscar sus materias primas es moneda corriente. Deben realizar caminatas de muchas horas al día para obtener lo que antes se veía desde sus casas como abundante. Esto también diversificó el trabajo, hay ahora personas que se encargan de la búsqueda del material y otros de realizar las piezas. Tal es el caso por ejemplo de las artesanas del chaguar en Chaco, o de los artesanos mascareros de Salta, de los cesteros de Palma caranday en Córdoba. Aparece entonces una fragmentación en el tradicional quehacer artesanal.

En muchos casos la materia prima se encuentra directamente inaccesible o en franca extinción, y los artesanos buscan otros materiales para reemplazarla y poder así seguir desarrollando su sustento, oficio y, a través de ello, su cultura.

Un ejemplo interesante es el de la localidad de Copacabana (pcia. de Córdoba) en donde la palma caranday fue desplazada/reemplazada en algún caso por el plástico. Se proveyó a los artesanos de la zona de una máquina para hilar botellas de pet y así comenzaron a realizar portatermos, canastas, paneras, bolsos, aplicando las técnicas y la expertise de la cestería a esta otra materia. Los artesanos ponen su saber hacer y su técnica, los cartoneros el material, plástico. El estudio Quinua llevó adelante este proyecto. Nos referiremos a él más adelante.

El reemplazo de la materia prima de origen por el plástico es controversial, genera apoyos y disidencias. Cierto es que la misma para algunas comunidades entra a formar parte de su cultura.

En referencia a un emprendimiento socio-ambiental realizado entre diseñadores y artesanos de la Comunidad Guaraní Ka Aguy Porá (de Misiones, Argentina) en el cual se propuso la reutilización de los plásticos, residuos de un hotel boutique, Lodge Yacutinga, para la elaboración de productos artesanales, dice Ximena González Eliçabe en una comunicación personal (2021): 
Me parece que no es justo que sean las comunidades las que tengan que ocuparse de reciclar la basura que generan los "blancos", ya que deberían ser ellas las comunidades- las primeras en tener acceso a las materias primas del monte, son sus guardianes, lo han utilizado en sus creaciones haciendo un uso equilibrado de ellas, se han ocupado de preservarlo.

Coincidimos en que esto no debería ser incentivado. Sin embargo, al día de hoy es una realidad de muchas comunidades y da lugar a cierto desarrollo económico que no puede ser invisibilizado. Encontramos este tipo de experiencias en varios lugares del país, promovidos por diferentes ámbitos de política pública, comunitaria y/o del tercer sector, y llevadas a cabo por comunidades de artesanas y artesanos la mayoría de las veces tradicionales.

¿Podemos llamar a estas obras que fusionan en diseños modernos una técnica tradicional tal el caso de la cestería con un nuevo material (por ejemplo, el plástico) como neoartesanías?

\section{La neoartesanía en otros contextos iberoamericanos}

En breve síntesis aludimos aquí a las diversas concepciones que, acerca de la neoartesanía, son utilizadas en distintos contextos iberoamericanos.

En Ecuador, sobre todo para Quito, surge este término como sinónimo de artesanía urbana contemporánea, y con él se hace referencia a un proceso de innovación de las artesanías urbanas basado en la recuperación y reforzamiento de las identidades culturales pero a través de la intervención del diseño. En tal sentido, en la propuesta que desarrolla Ferro (2017) se enfatiza el hecho de generar artesanías con identidad y calidad a partir de la asociación artesano/diseñador.

En España, la neoartesanía se define como "una corriente que fusiona las técnicas tradicionales de la producción manual con la metodología del diseño industrial uniéndose a las nuevas tecnologías y herramientas digitales como la impresión 3D, el corte láser, el diseño asistido, etcétera" (Miguel, 2019).

También se hace hincapié en la unión entre diseño y artesanía, que según Pérez Contreras (2016) ha demostrado ser en muchos países una estrategia exitosa en la conservación de su cultura, además de un activador de la economía.

En la Universidad de Granada, desde 2014 se viene desarrollando un proyecto que se propone fomentar la preservación del patrimonio cultural y natural y al mismo tiempo abrir líneas de investigación y temas de reflexión en torno a la creación artística y el diseño ofreciendo una visión contemporánea del patrimonio (García López y Bellido Gant, 2014). El proyecto se basa en el estudio y difusión de la creación, producción y comercialización de la artesanía a través del arte y el diseño.

En México, Ismael Rodríguez, creador del proyecto Neocrxft, vincula la tradición de la artesanía mexicana con las tendencias globales del diseño y define la "neoartesanía" como: "una construcción cultural, la acción que conecta por igual lo "hecho a mano" y el pensamiento abstracto, concebir cada pieza acorde a su naturaleza emotiva como antítesis 
de la producción industrial "perfecta”. Además, añade, "entendida como convergencia de disciplinas creativas, la neoartesanía brinda respuestas actuales que derivan de dinámicas sociales sobre una base de conocimiento colectivo".

De acuerdo con la propuesta de la organización público-privada Artesanías de Colombia la neoartesanía es la producción de objetos útiles y estéticos desde el marco de los oficios, en cuyos procesos se sincretizan elementos técnicos y formales procedentes de otros contextos socioculturales y otros niveles tecno-económicos, tiene una característica de transición hacia la tecnología moderna y/o la aplicación de principios estéticos de tendencia universal y/o académicos y tiende a destacar la creatividad individual expresada por la calidad y originalidad del estilo.

En Chile desde 1990 aparece según Fernández de Paz (2015) un interesante diálogo entre artesanos y diseñadores, que dio como resultado "unas piezas artesanas tan innovadoras como reconocibles en su tradición” (pp. 388-9). Si bien no se utiliza explícitamente el término neoartesanía, sí se da cuenta de ciertos rasgos que la caracterizan.

Se advierte la utilización de materias primas ancestrales en nuevos productos, objetos tradicionales elaborados con materiales recientes, manufacturas habituales trazadas ahora con diseños novedosos, maneras desconocidas de plasmar los colores en los textiles tradicionales o de insertarles nuevas texturas (Dannemann, 2003; Ubilla, 2011) También se ha incorporado la tecnología digital (3D y láser).

Es de notar que la asociación entre artesanía, diseño y tecnologías es un rasgo que se enfatiza en la mayor parte de estas definiciones. Se podría decir que uno de los cambios que se advierten en el campo artesanal a nivel nacional e internacional es, precisamente, la confluencia entre estas disciplinas.

\section{El trabajo colaborativo}

Para la UNESCO artesanía y diseño es una asociación estratégica en la cual el artesano aporta sus conocimientos y técnicas ancestrales, creatividad, tradición y excelencia en tanto, los diseñadores encuentran fuentes de inspiración para la creación y aportan visibilidad al sector de la artesanía. Hoy en día "el trabajo conjunto de artesanos y diseñadores, basados en acuerdos voluntarios de satisfacción mutua, pueden ofrecer alternativas culturales innovadoras, proveer de productos de calidad, conservando la biodiversidad y protegiendo el medio ambiente" (Vachéron y Vetrale, 2009).

El trabajo del artesano incluye el diseño y la ejecución de las obras. Produce artesanía y se expresa por medio de su producción manual, con intenciones artísticas, manifestaciones culturales, conceptos de utilidad. Los artistas populares en general transmiten individual o colectivamente, en forma comunitaria, a través de sus habilidades y expertise manual, sus sentimientos, emociones, cosmovisión.

El aporte de otros profesionales desglosa el diseño de la ejecución de la obra. Con variantes, hay muchas experiencias que van desde asesorías con respecto a tamaños, talles, colores o tratamiento de materiales, por ejemplo, hasta piezas completas o trabajos por encargo. También existen asociaciones que pueden ser respetuosas y favorecer a los arte- 
sanos económicamente. Muchas veces los profesionales pueden transmitir cuales son las necesidades del mercado, y así aumentar la producción. Pero ¿qué y quién es el mercado? Los roles y funciones de los actores se suelen volver complejos, y las relaciones entre artesanos y diseñadores pueden ser conflictivas. En un documento anterior (Unesco, 2005) se pone énfasis en recomendar al diseñador tratar al artesano como un socio creativo, no como un trabajador cualificado.

Hay consenso en que el trabajo colaborativo debe llevarse adelante reconociendo al artesano sus derechos autorales ya que intercambia sus saberes y experiencias con los diseñadores. Muchas veces se lo invisibiliza lo que atenta contra las buenas prácticas y las posibilidades que ofrece esta modalidad laboral (Amarilla, 2019).

Si bien la artesanía puede valerse del diseño para adaptarse a las necesidades actuales de materiales, comunicación y cercanía a las nuevas tecnologías, dice Pérez Contreras (2016), el diseñador puede aprender mucho de arraigo cultural, espiritualidad y sabiduría popular a través del artesano.

En la Argentina hay distintos emprendimientos en los cuales diseñadores y artesanos (urbanos o tradicionales) trabajan conjuntamente, con diferentes modalidades. Por ejemplo, el trabajo llevado adelante por Quinua Arquitectura y el apoyo de una ONG internacional, INCIDE, con la comunidad de artesanos cesteros de la localidad de Copacabana (al norte de la provincia de Córdoba), que elaboran productos con la palma caranday. Los diseñadores aportaron desde el "diseño participativo" en una primera instancia, asesorando sobre marca, tipo de productos y tamaños, y además, desarrollando un proyecto que combina el diseño con el activismo social.

Podemos hacer referencia también, al trabajo que realiza el diseñador Cristian Mohaded, referente del diseño latinoamericano en la escena contemporánea global, quien en distintos proyectos se vincula con artesanos/as de distintas provincias argentinas para llevar a cabo sus propuestas creativas, tal es el caso por ejemplo, de sus piezas elaboradas con un cestero catamarqueño para una marca de iluminación de la provincia de Córdoba o bien, las que ambos efectúan en relación a temas esculturales.

"Hay una relación de ida y vuelta, de construcción (con el artesano) involucrándonos en el proyecto" dice Mohaded en una entrevista realizada en 2020 por Ximena González Eliçabe. En esta relación de diseño colaborativa es fundamental para él, el respeto, la confianza y la empatía.

Otro ejemplo es de Alwa Toba, una organización en la cual dos hermanas, la Arq. Yandyra Susana Chagra y la Lic. Mariana Sabina Chagra, trabajan conjuntamente con comunidades de artesanas indígenas de Formosa. Su objetivo es "realizar objetos útiles y estéticos de uso cotidiano en los que conectan pasado y presente, combinando técnicas y materias primas tradicionales con diseños contemporáneos".

Es de mencionar asimismo el trabajo colaborativo entre artesanas urbanas y tradicionales. Se trata del proyecto Ampara Textil que llevan a cabo las artesanas joyeras y textiles Lilia Breyter y Silvia Roldán con colectivos de tejedoras del norte argentino con la finalidad de visibilizar los tejidos tradicionales realizando objetos de alta circulación como joyas. Piezas que "testimonian esa riqueza artesanal aunada a nuestro trabajo de costura, bordado, estampado y teñido natural” (Breyter). 


\section{Consideraciones finales}

La neoartesanía propone un diálogo entre la tradición, la innovación, el pasado, el presente, lo local y lo global. Como dice Santos Capa "explora nuevas identidades, articula la naturaleza con la tecnología, lo racional y lo emocional, buscando un equilibrio entre la ecología y la sostenibilidad" (Capa, 2020). Retomando lo dicho, consideramos que se trata de un fenómeno que se da en el campo de las artesanías contemporáneas, y que se caracteriza por la fusión entre lo tradicional y lo moderno, entre materiales y técnicas, el uso de nuevos materiales y tecnologías. Estos rasgos van configurando su propia identidad como objeto portador de estética, funcionalidad y simbolismo. Objeto que es necesario analizar en función de las tendencias socioculturales actuales, los cambios y las nuevas prácticas que se observan en la sociedad y que afectan su producción, circulación y consumo. Entre sus productores encontramos la convergencia de artesanos tradicionales y contemporáneos, así como la participación de otros actores como los diseñadores en particular.

Con respecto a ellos admitimos, sin legitimar aquellos elaborados por ejemplo con materiales industriales como el plástico, no para justificar la depredación de las materias primas naturales que obligan a algunas comunidades de artesanos a utilizarlo, sino teniendo en cuenta que, al igual que la incursión en las nuevas tecnologías resultan novedosas y forman parte de una realidad social vigente que atraviesa el campo artesanal.

¿Se trata la impresión 3D, 4D de una nueva técnica artesanal? ¿Permanece el proceso creativo, la propuesta estética y la sustentabilidad al incorporar recursos ecológicos como materia prima? También hay coincidencia en la transformación, manejo y conocimiento que esta materia requiere, así como de las técnicas. Mantiene todos estos componentes y cambia de una forma deslumbrante la inserción de una máquina impresora del objeto. ¿Cual es la relación ahora delartesano/a con el objeto?

Para abordar el fenómeno de la neoartesanía hemos partido de un conjunto de enunciados que, en permanente proceso, van construyendo diferentes interpretaciones acerca de ella, es decir, su significación, y que nosotros recuperamos a través del discurso de los protagonistas.

Cuando decimos discurso no nos referimos sólo a expresiones verbales (orales o escritas) sino también a los distintos lenguajes (o sistemas de signos) visuales e indiciales (o comportamentales) que configuran ese universo significativo. Cabe aclarar que lo que hace perceptible e identificable a cualquier fenómeno que emerge en un momento y en una sociedad determinados es, precisamente, el hecho de ser enunciable en alguna de las semiosis vigentes (Magariños de Morentin, 2008).

Los artesanos conforman la noción de neoartesanía mediante sus obras, sus palabras, sus comportamientos respecto de este fenómeno social así como lo hacen los especialistas, académicos, agentes culturales, técnicos, con coincidencias, contradicciones, complementariedades.

Nuestra intención es reflexionar sobre este fenómeno, en función de dicha heterogeneidad, estando atentos a las transformaciones y tendencias del campo artesanal. Y más aún, nos preguntamos, ¿qué cambios son posibles de imaginar a partir de lo que percibimos hoy? 


\section{Referencias}

Amarilla, R. (2020) “Prácticas del Trabajo Colaborativo con artesanos y artesanas migrantes". En: Cuadernos del Centro de Estudios en Diseño y Comunicación [Ensayos] Año 24 (111) 2020/2021. Buenos Aires: Facultad de Diseño y Comunicación Universidad de Palermo. Amarilla, R. (2019). "Botones Pastelito”. En: Revista Chilena de Diseño, rchd: creación y pensamiento. Universidad de Chile 2019, 4(7) http://rchd.uchile.cl

Benito, N. (29 de octubre de 2019). Neoartesanía: volver a los orígenes, pero con el trampolín de la tecnología. El Periódico. Disponible en https://www.elperiodico.com/es/activos/ valores/20191002/neoartesania-volver-a-los-origenes-pero-con-el-trampolin-de-la-tec nologia-7660433

Bialogorski, M. y Fritz, P. (2011). ¿Qué son las artesanías contemporáneas? Las guías de la Comisión para la Preservación del Patrimonio Histórico Cultural de la Ciudad de Buenos Aires. Buenos Aires.

Bialogorski, M. (2017). "Reinterpretando el patrimonio artesanal: los estudios de visitantes en la gestión de museos”. Mirta Bialogorski y María Marta Reca (comp.) En: Museos y visitantes. Ensayos sobre estudios de público en Argentina. Buenos Aires: ICOM Argentina. Pp.69-93

Cortazar, A. R. (1976). Ciencia Folklórica Aplicada. Reseña teórica y experiencia argentina. Buenos Aires: Fondo Nacional de las Artes.

Dannemann, M. (2003). “Los cambios en la plástica folklórica”. En 30 Muestra Internacional de Artesanía Tradicional. Santiago: UC.

Diaz, V. (2018). “¿Una moda responsable? Emprendimientos de diseño de indumentaria con producción artesanal de pueblos originarios y rurales desde la perspectiva de la responsabilidad social empresarial". En: Ciencias Económicas, 1: 9-25. Disponible en https:// bibliotecavirtual.unl.edu.ar/publicaciones/index.php/CE/article/view/7737

Fernández de Paz, E. (2015). "La valorización artesana y su repercusión turística. El caso de Chile”. En: PASOS. Revista de Turismo y Patrimonio Cultural. 13 (2): 375-393. Special Issue. España: Universidad de La Laguna El Sauzal (Tenerife).

Ferro, D. (2017). Neoartesanía quiteña:una propuesta sustentable. Serie Magíster Vol. 214, Quito (Ecuador) Universidad Andina Simón Bolívar, Sede Ecuador. Corporación Editora Nacional.

García Canclini, N. (1989). Culturas híbridas. Estrategias para entrar y salir de la modernidad. Buenos Aires: Ed. Sudamericana

García López, A. y Bellido Gant, M. L. (comp) (2014). Entre Granada y Tetuán.Artesanía, diseño y arte contemporáneo. CEI Biotic Granada. New York (USA) - España: Editorial ATRIO S.L. y Editorial Downhill Publishing LLC.

García López, A. (2014). “Transferencias culturales entre artesanía, arte y diseño”. En: Entre Granada y Tetuán. Artesanía, diseño y arte contemporáneo. García López, Ana y María Luisa Bellido Gant (comp) CEI Biotic Granada. New York (USA) - España: Editorial ATRIO S.L. y Editorial Downhill Publishing LLC.

González Eliçabe, X. (9 de octubre 2020). Entrevista a Cristian Mohaned. 3 webinar Diseño y Artesanía Universidad de Palermo. https://youtu.be/wkP4-Hb6QIA

Magariños de Morentin, J. (2008). La semiótica de los bordes. Buenos Aires: Comunicarte. 
Pérez Contreras, T. (2016). "Neoartesanía y diseño: patrimonio e industria cultural como elementos de identidad”. En: Anjhara Gómez Aragón (coord.) (2016) Japón y “Occidente” El patrimonio cultural como punto de encuentro. Sevilla. España: 313-320. Disponible en file://C:/Users/pc/Downloads/Dialnet-Japon y Occidente-654205.pdf

Piñeiro, A. “¿Puede la impresión 3D considerarse artesanía?” 07 mar 2020. Plataforma Arquitectura. Accedido el 22 Feb 2021. Disponible en <https://www.plataformaarquitectura. $\mathrm{cl} / \mathrm{cl} / 934562 /$ puede-la-impresion-3d-considerarse-artesania $>$

Santos Capa, J. (2020). “Construyendo el relato” II Jornadas de ADA. Artesanía +Diseño+ Arte. Organizado por Medialab UGR, la Facultad de Bellas Artes de Granada y el Centro Albayzín. Disponible en https://www.youtube.com/watch?v=ifz9F2S6gBU

Ubilla, M. (2011). “Artesanía/Diseño UC”. En 38 Muestra Internacional de Artesanía Tradicional. Santiago: UC., 4-7.

UNESCO (2005). Encuentro entre Diseñadores y Artesanos: Guía Práctica. Disponible en http://unesdoc.unesco.org/images/0014/001471/147132s.pdf.

Vachéron, F. y Vetrale, S. (2009). Dossier UNESCO. Artesanía y Diseño 2. Taller A+D. Encuentro en Santiago de Chile, 13Disponible en http://diseno.uc.cl/publicacion/

\section{Otras fuentes}

Amarilla, R. (14 de noviembre 2020) "Artesanías siglo XXI: innovaciones en manos de artesanos tradicionales de comunidades originarias". https://www.youtube.com/watch?v=dZo8naZERbQ

Salazar, T. y González, J. (9 de diciembre 2020). Podcast Artesanía Posindustrial. Nodos de manufactura y digitalización distribuida (NOMAD)https://www.youtube.com/ watch?v=6dFONauyt Jw

https://www.colombia.com/tecnologia/eventos/sdi/75320/etno-artesania-neo-artesania -y-eco-artesania-tendencias-que-marcan-la-historia

https://woodartweb.wordpress.com/about/

https://coolhuntermx.com/neocrxft-neoartesania/

https://artesaniasdecolombia.com.co/PortalAC/GlosarioPalabra/artesania-contemporanea -o-neoartesania_48

https://proyectomenosesmas.com.ar/DO.html

\footnotetext{
Abstract: José Hernández Folk Art Museum is focused on crafts and artisans as cultural productions and producers. As an important actor in the patrimonialization processes, the museum closely follows any change in craft field according to places and historical moments.

It has been visualized for a long time, certain transformations in the production of handicrafts that, although they are different to each other, lead us to think if we could identify them as a new phenomenon: "neoartesanía".
} 
These are objects that join traditional components, elements, or processes with other innovative ones. We discover that this production occurs in collaborative work between craftmen, designers, technicians, or other professionals who converge on the same craftman. It is also overlapped by the problem of sustainability.

In this work we will refer to how this phenomenon is constructed in Argentina, taking into account the dispersion of elements that constitute it, how the notion of "neoartesanía" is configured in the discourse of technicians, craftmen and researchers, considering particular cases and contexts. We will also make a brief reference to how it is understood in other Ibero-American areas. Far from defining a category, we are interested in capturing the several dimensions that "neoartesanía" shows as part of a more comprehensive social phenomenon such as the craft field in the current context of globalization.

Keywords: "neoartesanía" - craft field - design - sustainability - collaborative work.

Resumo: O Museu de Arte Popular José Hernández privilegia o artesanato e os artesãos como produções e produtores culturais. Enquanto ator fundamental nos processos de patrimonialização, está atento às mudanças que o campo dos artesãos vivencia de acordo com os lugares e momentos históricos.

Há já algum tempo, visualizamos certas transformações na produção de artesanato que, embora diferentes entre si, nos levam a questionar se poderíamos identificá-las como um fenômeno novo: o "neo-artesanato".

São objetos que unem componentes, elementos ou processos tradicionais a outros inovadores. Verificamos que esta produção começa a ocorrer em trabalhos colaborativos entre artesãos, comunidades de artesãos, designers, técnicos, outros profissionais ou são realizados pelo mesmo artesão. Também é atravessada pelo problema da sustentabilidade.

Neste trabalho iremos nos referir a como esse fenômeno se constrói na Argentina, levando em consideração a dispersão dos elementos que o constituem, e como a noção de neo-artesanato se configura nos discursos de técnicos, artesãos e pesquisadores, levando em consideração casos particulares e contextos. Faremos também uma breve referência a como isto é entendido em outras áreas ibero-americanas. Longe de definir uma categoria, nos interessa captar as várias dimensões que o neo-artesanato apresenta como parte de um fenômeno social mais abrangente como por exemplo o campo do artesanato no atual contexto de globalização.

Palavras chave: neo-artesanato - campo dos artesãos - design - trabalho colaborativo sustentabilidade.

[Las traducciones de los abstracts fueron supervisadas por el autor de cada artículo] 